\title{
Anticancer effects of curcumin on nude mice bearing lung cancer A549 cell subsets SP and NSP cells
}

\author{
XIAOJIANG LI ${ }^{1 *}$, SHAOJUN MA ${ }^{2 *}$, PEIYING YANG ${ }^{1}$, BINXU SUN $^{1}$, YING ZHANG ${ }^{1}$, \\ YUEHONG SUN ${ }^{3}$, MEIMEI HAO ${ }^{4}$, RUIYU MOU ${ }^{1}$ and YINGJIE JIA ${ }^{1}$
}

\begin{abstract}
Departments of ${ }^{1}$ Oncology and ${ }^{2}$ Interventional Vascular, First Teaching Hospital of Tianjin University of Traditional Chinese Medicine, Tianjin 300193; ${ }^{3}$ Department of Radiochemotherapy, Cangzhou Hospital of Integrated Traditional Chinese Medicine and Western Medicine, Cangzhou, Hebei 061899; ${ }^{4}$ Department of Oncology, Shanxi Provincial Hospital of Traditional Chinese Medicine, Taiyuan, Shanxi 710003, P.R. China
\end{abstract}

Received November 17, 2017; Accepted July 3, 2018

DOI: $10.3892 / \mathrm{ol} .2018 .9488$

\begin{abstract}
Curcumin is a key polyphenolic curcuminoid extracted from the root of turmeric rhizome Curcuma longa Linn, which is a frequently used Chinese herb for the treatment of cancer. The aim of the present study was to investigate the mechanism of the inhibitory effects of curcumin on nude mice with lung cancer A549 cell subsets side population (SP) and non-SP (NSP) cells. BALB/c mice were subcutaneously injected with the tumor cells of A549 SP or NSP subsets consisting of $1 \times 10^{9}$ cells $/ 1$ ( $0.2 \mathrm{ml}$ in total). After 16 days of inoculation with A549, the mice were intraperitoneally injected with curcumin $(100 \mathrm{mg} / \mathrm{kg}, 0.2 \mathrm{ml})$ once every other day, eight times in total. A series of assays were performed to detect the effects of curcumin on: i) Tumor weight and size; ii) Notch and hypoxia inducible factor 1 (HIF-1) mRNA expression by quantitative polymerase chain reaction; and iii) vascular endothelial growth factor (VEGF) and nuclear factor- $\kappa \mathrm{B}$ $(\mathrm{NF}-\kappa \mathrm{B})$ by immunohistochemistry. It was determined that curcumin decreased the tumor weight and size, downregulated the expression of Notch and HIF-1 mRNA and suppressed the $\mathrm{VEGF}$ and $\mathrm{NF}-\kappa \mathrm{B}$ expression. These results indicated that curcumin inhibited lung cancer growth through the regulation of angiogenesis mediated by VEGF signaling.
\end{abstract}

\section{Introduction}

Lung cancer is the leading cause of cancer-associated mortalities in males and the second leading cause of cancer-associated

Correspondence to: Dr Yingjie Jia, Department of Oncology, First Teaching Hospital of Tianjin University of Traditional Chinese Medicine, 314 An Shan Xi Dao, Tianjin 300193, P.R. China

E-mail: jiayjjiayj@126.com

*Contributed equally

Key words: curcumin, lung cancer, vascular endothelial growth factor, nuclear factor- $\mathrm{\kappa} \mathrm{B}$ mortalities in females, with $\sim 1.6$ million new lung cancer cases (1). Lung cancer caused 1,590,000 mortalities in 2012 globally and currently is the leading cause of cancer-associated mortality (2). For developed and developing countries, lung cancer remains the leading cause of cancer-associated mortalities and a global challenge to human health, particularly to those who are heavy smokers (3). In China, due to pollution from the environment, indoor air, occupations and cooking fumes, females have an increased lung cancer incidence rate (21.3 cases/100,000 females) in 2000, compared with females in European countries, even though they have a reduced prevalence of smoking (4). Among all lung cancer types in 2002, non-small cell lung cancer (NSCLC) accounts for $\sim 80 \%$ of cases, the majority of which are at an advanced stage and unresectable when diagnosed (5). In 2008, the 1-, 2-, 3-, 4- and 5-year survival rate of stage IV NSCLC in China was 44, 22, 13, 9 and 6\%, respectively (6). Surgery, radiotherapy, combined chemoradiotherapy and adjuvant chemotherapy are the most common treatments for NSCLC. Previously, targeted therapies, including epidermal growth factor receptor- and anaplastic lymphoma kinase-targeted therapies, are promising effective methods to personalize the treatment of lung cancer; however, resistance to these treatments and the side effects of the radiotherapy or chemotherapy are challenging problems (7). According to the increased Hoechst 33342 dye efflux activity, NSCLC-initiating cells have been isolated from human lung cancer cell lines (8). Cancer side-population (SP) represents a sub-population of stem-like cancer cells that have an important role in drug resistance (9). The Hoechst dye low SP cells are enriched for tumor-initiating activity, compared with non-SP (NSP) cells, and express elevated ATP binding cassette (ABC) subfamily $\mathrm{G}$ member 2 and other multi-drug resistance transporters that may mediate therapeutic resistance (10).

Alternative complementary and alternative medicines (CAM) display an attractive efficacy in the treatment of cancer. The effect of Traditional Chinese Medicine, a type of CAM, in treating lung cancer has attracted the attention of a number of medical organizations $(11,12)$. Curcumin is a key polyphenolic curcuminoid extracted from the root of turmeric rhizome Curcuma longa Linn, which is a frequently used Chinese herb for the treatment of cancer, including 
colon cancer, central nervous system diseases and respiratory diseases (13-15). Currently, a number of studies have demonstrated the therapeutic effect of curcumin on cancer, particularly lung cancer $(16,17)$. For instance, it has been indicated that curcumin exerted a strong inhibition effect on lung cancer cells, characterized by the regulation of the mitochondrial apoptosis pathway (18). Liu et al (19) reported that curcumin-induced autophagy has anticancer effects on human lung adenocarcinoma cell line A549; however, studies are yet to be conducted to assess the effect of curcumin on lung cancer in vitro and its different role on A549 cell subsets SP and NSP cells. In this present study, the anticancer effects of curcumin on nude mice bearing lung cancer A549 cell subsets SP and NSP cells were assessed; therefore, the present study was designed to observe the effects of curcumin on BALB/c mice subcutaneously injected with the tumor cells of A549 SP or NSP subsets. To accomplish the stated objectives, a series of indexes were performed including: The tumor weight and size; Notch and hypoxia inducible factor 1 (HIF-1) mRNA expression; and vascular endothelial growth factor (VEGF) and nuclear factor- $\kappa \mathrm{B}(\mathrm{NF}-\kappa \mathrm{B})$ expression.

\section{Materials and methods}

Animal grouping and treatment. The present experiment was approved by the Animal Care Committee of Tianjin University of Traditional Chinese Medicine (Tianjin, China) and in accordance with the UK Animals (Scientific Procedures) Act of 1986 (20). A total of 40 male nude BALB/c mice aged 4-6 weeks, weighing 18 \pm 2 g (purchased from Beijing Vital River Laboratory Animal Technology Co., Ltd, Beijing, China) were kept in standard cages at $25 \pm 1^{\circ} \mathrm{C}$ under a $12 / 12 \mathrm{~h}$ light/dark cycle and fed a rodent standard diet with free access to water. The mice were randomly divided into four groups, with each group containing 10 mice. For the group SP, mice were subcutaneously injected with the tumor cells of A549 SP subsets consisting of $1 \times 10^{9} / 1$ cells $(0.2 \mathrm{ml}$ in total). According to a previous study (21), high dosage $(500 \mathrm{mg} / \mathrm{kg} /$ day $)$ or low dosage (100 mg/kg/day) of curcumin had no clear difference from that of the control group, in terms of eight hematological indexes, general dissection and pathology. Additionally, curcumin was safe if taken 80 days continuously under the dosage $100 \mathrm{mg} / \mathrm{kg} / \mathrm{day}$; therefore, the low dose $(100 \mathrm{mg} / \mathrm{kg})$ was selected in the present experiment. For the group SP+curcumin, mice were subcutaneously injected with the tumor cells of A549 SP subsets consisting of $1 \times 10^{9} / 1$ cells ( $0.2 \mathrm{ml}$ in total), combined with $100 \mathrm{mg} / \mathrm{kg}$ curcumin. For the group NSP, mice were subcutaneously injected with the tumor cells of A549 NSP subsets consisting of $1 \times 10^{9} / 1$ cells $(0.2 \mathrm{ml}$ in total). For the group NSP+curcumin, mice were subcutaneously injected with the tumor cells of A549 NSP subsets consisting of $1 \times 10^{9} / 1$ cells $(0.2 \mathrm{ml}$ in total $)$, combined with curcumin. After 16 days of inoculation with A549, the mice were intraperitoneally injected with curcumin $(100 \mathrm{mg} / \mathrm{kg}$, $0.2 \mathrm{ml}$ ) once every other day, eight times in total. For the mice without curcumin treatment, saline $(25 \mathrm{ml} / \mathrm{kg}, 0.2 \mathrm{ml})$ was used as the control.

A549 cell culture. Lung cancer cell line A549 were purchased from the Institute of Basic Medical Sciences of the China
Science Academy (Beijing, China) and cultured in Dulbecco's modified Eagle's medium containing $10 \%$ fetal bovine serum and 1\% penicillin and streptomycin (Sigma-Aldrich; Merck KGaA, Darmstadt, Germany) in a humidified $5 \% \mathrm{CO}_{2}$ atmosphere at $37^{\circ} \mathrm{C}$. The A549 cells were passaged at $90 \%$ confluence, with 2-3 passages/week.

SP and NSP cells separation and soft agar colony formation assay. The immunomagnetic-bead sorting method (22) was used to separate SP $\left(\mathrm{CD} 133^{+}\right)$cells and NSP cells (CD133') from the A549 cell line. Briefly, A549 cells were incubated with CD133 immunomagnetic beads (cat. no. 130-100-857; Miltenyi Biotec, Inc., Cambridge, MA, USA) for $30 \mathrm{~min}$ at $4^{\circ} \mathrm{C}$. For magnetic separation, separation column was used to retain the positive cells associated with the beads. The $\mathrm{CD}_{133}{ }^{+}$cells obtained from the column were centrifuged at $300 \mathrm{x} \mathrm{g}$ at room temperature for $5 \mathrm{~min}$ and resuspended in $\mathrm{PBS}$. $\mathrm{CD}_{133^{+}}$cells were incubated with $0.1 \%$ Triton $\mathrm{X}-100$ for $10 \mathrm{~min}$ at room temperature and incubated with $3 \% \mathrm{H}_{2} \mathrm{O}_{2}$ at room temperature for $30 \mathrm{~min}$. CD133 primary antibody (1:100; cat. no. sc-30219; Santa Cruz Biotechnology, Inc., Dallas, TX, USA) was added and incubated at $4^{\circ} \mathrm{C}$ overnight, followed by horseradish peroxidase-conjugated goat anti-rabbit secondary antibody (1:500; cat. no. ab6721; Abcam, Cambridge, UK) incubation for $40 \mathrm{~min}$ at $37^{\circ} \mathrm{C}$. Add DAB for $2 \mathrm{~min}$. The sorted SP cells and NSP cells at logarithmic growth phase were adjusted at a cell density of 400 cells/ml and were cultured with 2 X RPMI-1640 culture medium (Thermo Fisher Scientific, Inc., Waltham, MA, USA) in a 6 -well plate coated with $0.5 \%$ agarose and $2 \mathrm{X}$ RPMI-1640 medium (1:1). Pipette $2 \mathrm{ml}$ the cell-agar mixture onto the solidified bottom layer of agar in 6-well plate and allow it to solidify for $30 \mathrm{~min}$ at room temperature. When the upper layer was coagulated, the cells were cultured for 3 weeks in a humidified $5 \% \mathrm{CO} 2$ atmosphere at $37^{\circ} \mathrm{C}$. The cell colony rate was tested by MTT staining. Briefly, $5 \mathrm{mg} / \mathrm{ml}$ MTT were added into each well $(1 \mathrm{ml} /$ well $)$ and incubated for $1 \mathrm{~h}$ at $37^{\circ} \mathrm{C}$. The number of colonies with $>50$ cells was counted under a light microscope (x40; ECLIPSETs2; Nikon Corporation, Tokyo, Japan), and the colony clone rate was calculated with the formula: Cell colony rate=(average cell colony number/total cells) x $100 \%$.

Measurement of tumor size and weight. For the tumor-bearing mice, tumor size and weight were used for evaluation of the effect of curcumin on tumor growth. On the last day of the experiment, the tumor size was calculated according to the formula: $\left(\mathrm{LxS}^{2}\right) \times 0.5$, where $\mathrm{L}$ represents the greatest diameter of the tumor and $\mathrm{S}$ represents the shortest diameter of the tumor (23). Additionally, $200 \mathrm{mg} / \mathrm{kg}$ pentobarbital was used to anesthetize all mice. Subsequently, the mice were anaesthetized with aether and used immediately for determination of tumor weight, which was determined by weighing the wet tumor.

Notch-1 mRNA quantification by reverse transcription-quantitative polymerase chain reaction ( $R T-q P C R)$. mRNA was detected using RT-qPCR and the $2^{-\Delta \Delta C q}$ method (24). Total RNA of tumor tissue was isolated and analyzed using a Reverse Transcriptase kit (Suzhou 
GenePharma Co., Ltd., Suzhou, China. http:/www.genepharma.cn/), according to the manufacturer's protocols. A total of $2 \mu \mathrm{l}$ cDNA synthesized by the RevertAid First Strand cDNA Synthesis kit (Thermo Fisher Scientific, Inc.) was used for PCR. The level of mRNA was detected using the Maxima $\mathrm{SYBR}^{\circledR}$ Green qPCR Master mix (Fermentas; Thermo Fisher Scientific, Inc.). qPCR was conducted at $95^{\circ} \mathrm{C}$ for $10 \mathrm{~min}$ followed by 40 cycles of $95^{\circ} \mathrm{C}$ for $15 \mathrm{sec}$ and $60^{\circ} \mathrm{C}$ for $60 \mathrm{sec}$. The following primer sequences were used: Notch-1, forward, 5'-TCCGCGGCTCCATCGTCTACC-3', and reverse, 5'-CTG CACGGCCTGGATCTTGTA-3'; HIF-1, forward, 5'-TCG GACAGCCTCACCAGACAG-3' and reverse, 5'-TTCCAT TTTTCGCTTCCTCTGA-3'; and $\beta$-actin, forward, 5'-TGC TGTCCCTGTATGCCTCT-3' and reverse, 5'-TTTGATGTC ACGCACGATTT-3'. RT-qPCR was performed in duplicate and relative expression levels of Notch-1 and HIF-1 were normalized to $\beta$-actin expression.

VEGF and $N F-\kappa B$ expression by immunohistochemistry. All of the mice were sacrificed and the lung cancer tissue was removed for $\mathrm{VEGF}$ and $\mathrm{NF}-\kappa \mathrm{B}$ expression detection. Briefly, tumor tissues were fixed with $4 \%$ paraformaldehyde overnight at room temperature, and then paraffin embedded tissue was cut into $4-\mu \mathrm{m}$ sections and were deparaffinized in histoclear (National Diagnostics, Atlanta, GA, USA) for $10 \mathrm{~min}$, rehydrated with a graded ethanol series $(100,95$, $90,80,60$ and $30 \%$ ) and washed with $0.01 \mathrm{M} \mathrm{PBS}$ at room temperature. Endogenous peroxidase was inactivated with $3 \%$ hydrogen peroxide at room temperature for $30 \mathrm{~min} .10 \%$ goat serum (Wuhan Boster Biological Technology, Ltd. Wuhan, China) was used to block non-specific antibodies for $30 \mathrm{~min}$ at room temperature, then the sections were incubated with anti-VEGF (antigen recognition site is $\mathrm{H}-70$; cat. no. sc-13083) or anti-NF- $\mathrm{B}$ (antigen recognition site is C-20; cat. no. sc-372) (1:500; Santa Cruz Biotechnology, Inc.) at $4^{\circ} \mathrm{C}$ overnight. Following washing with $0.01 \mathrm{M}$ PBS, the sections were incubated with the horseradish peroxidase-conjugated goat anti-rabbit secondary antibody (cat. no. 31460; Thermo Fisher Scientific, Inc.) at $37^{\circ} \mathrm{C}$ for $1 \mathrm{~h}$, followed by counterstaining with hematoxylin for $5 \mathrm{~min}$ at room temperature. Subsequently, the slices were coverslipped and observed by a light microscope (x40; cat. no. LSI3-FV1000-Inverted; Olympus Corporation, Tokyo, Japan) and Image-Pro Plus 6.0 software (Media Cybernetics, Inc., Rockville, MD, USA).

Statistical analysis. The results are presented as the mean \pm standard deviation of the mean. SPSS 16.0 (SPSS, Inc., Chicago, IL, USA) and Excel (Microsoft Corporation, Redmond, WA, USA) software were used for further data and statistical analysis. One-way analysis of variance combined with post-hoc test of Newman-Keuls were used to determine statistically significant differences among the groups. $\mathrm{P}<0.05$ was considered to indicate a statistically significant difference.

\section{Results}

Isolation and identification of A549 lung adenocarcinoma stem cells. Among the normal cultured A549 cells (Fig. 1A),
NSP cells were negatively stained by CD133 (Fig. 1B); however, lung cancer stem cells, SP cells, were positively stained by CD133, characterized by brown staining (Fig. 1C and D). The soft agar colony formation assay demonstrated that SP and NSP cells had colony formation ability in vitro after 21 days of culture. The NSP colony formation rate was $13.33 \pm 1.76 \%$, which was significantly reduced compared with SP cells $(30.67 \pm 2.57 \% ; \mathrm{P}<0.05)$.

Effect of curcumin on tumor size and weight. To measure tumor growth inhibition caused by curcumin treatment, tumor tissues were measured and weighed. Fig. 2A indicated that the tumor weight $(1.48 \pm 0.16 \mathrm{~g})$ of group NSP was notably reduced, compared with group SP $(1.11 \pm 0.13 \mathrm{~g})$, indicating that the tumor growth of SP cells was increased, compared with NSP cells. Following the treatment of curcumin, compared with the group SP and group NSP, the tumor weight of group SP+curcumin was decreased by $32.7 \%$, which was less than the decrease in the group NSP+curcumin (45.1\%). As for the tumor volume (Fig. 2B), the tumor size of group SP $\left(0.58 \pm 0.09 \mathrm{~mm}^{3}\right)$ had no significant difference, compared with group NSP $\left(0.44 \pm 0.08 \mathrm{~mm}^{3}\right)$. Following treatment with curcumin, compared with the group SP, the tumor size of group SP+curcumin significantly decreased by $35.2 \%$ $(\mathrm{P}<0.05)$; however, compared with the group NSP, treatment with curcumin, the tumor volume of group NSP+curcumin was not significantly reduced $(\mathrm{P}>0.05)$.

Effect of curcumin on Notch-1 and HIF-1 mRNA expression. Notch-1 and HIF-1 mRNA expression was analyzed by the relative ratio of Notch-1 and HIF-1, individually, against $\beta$-actin. It was determined that Notch-1 and HIF-1 mRNA expression levels in groups SP and NSP had no significant difference ( $\mathrm{P}>0.05$; Fig. $3 \mathrm{~A}$ and $\mathrm{B})$. Curcumin significantly suppressed the mRNA expression of Notch-1 in the group $\mathrm{SP}+$ curcumin and group NSP+curcumin by $53.2 \%(\mathrm{P}<0.01)$ and $52.7 \%(\mathrm{P}<0.05)$, respectively. Additionally, HIF-1 mRNA expression was also inhibited by curcumin in the group $\mathrm{SP}+$ curcumin and group NSP+curcumin by $48.8 \%(\mathrm{P}<0.01)$ and $34.4 \%(\mathrm{P}<0.05)$, respectively.

Effect of curcumin on VEGF and $N F-\kappa B$ expression. To assess the in vivo protective effect of curcumin against tumor angiogenesis, VEGF and NF- $\mathrm{NB}$ expression was evaluated via immunohistochemistry. The result of immunohistochemistry demonstrated that the VEGF (Fig. 4A and B) expressed in groups SP and NSP, and were primarily located in the cytoplasm and characterized by dark brown staining; however, following eight treatments of curcumin, VEGF (Fig. 4C and D) immunoreactivity was not prominent, indicating a notable suppression of VEGF in the tumor tissue. NF- $\kappa \mathrm{B}$ expression (Fig. 5A and B) was significantly increased, while suppressed by curcumin (Fig. 5C and D). Compared with group SP, the expression of VEGF in the group SP+curcumin was notably decreased; however, curcumin treatment did not inhibit the expression of VEGF for the mice subcutaneously injected with the NSP cells. For the NF- $\kappa \mathrm{B}$ expression, compared with group SP or NSP, curcumin treatment did not significantly suppress the expression in mice subcutaneously injected with SP or NSP cells $(\mathrm{P}<0.01)$. 

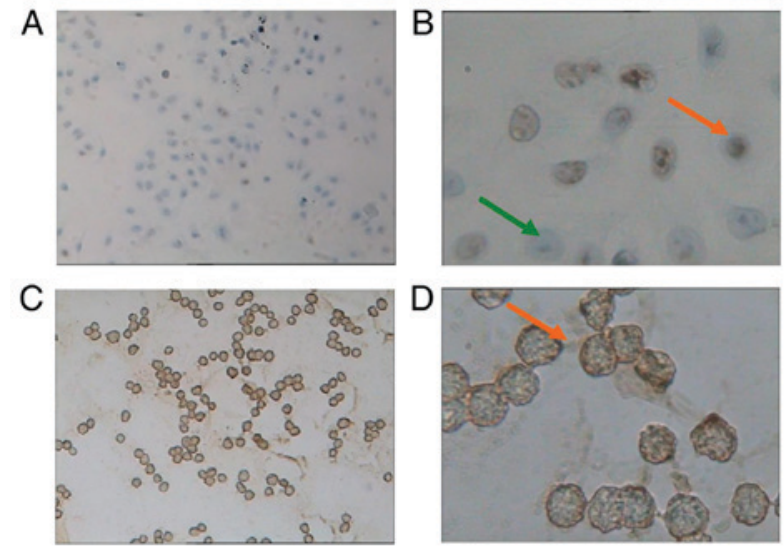

Figure 1. Light microscopy of A549 cells and SP cells (stained with CD133+) following A549 sorting. (A) Normal cultured A549 cells (x100 magnification). (B) NSP cells were negatively stained by CD133, indicated by a green arrow. SP cells were positively stained by CD133, indicated by an orange arrow (x400 magnification). (C) The sorted SP cells (x100 magnification). (D) SP cells were positively stained by CD133, characterized by brown staining and indicated by an orange arrow (x400 magnification). SP, side population; NSP, non-SP.
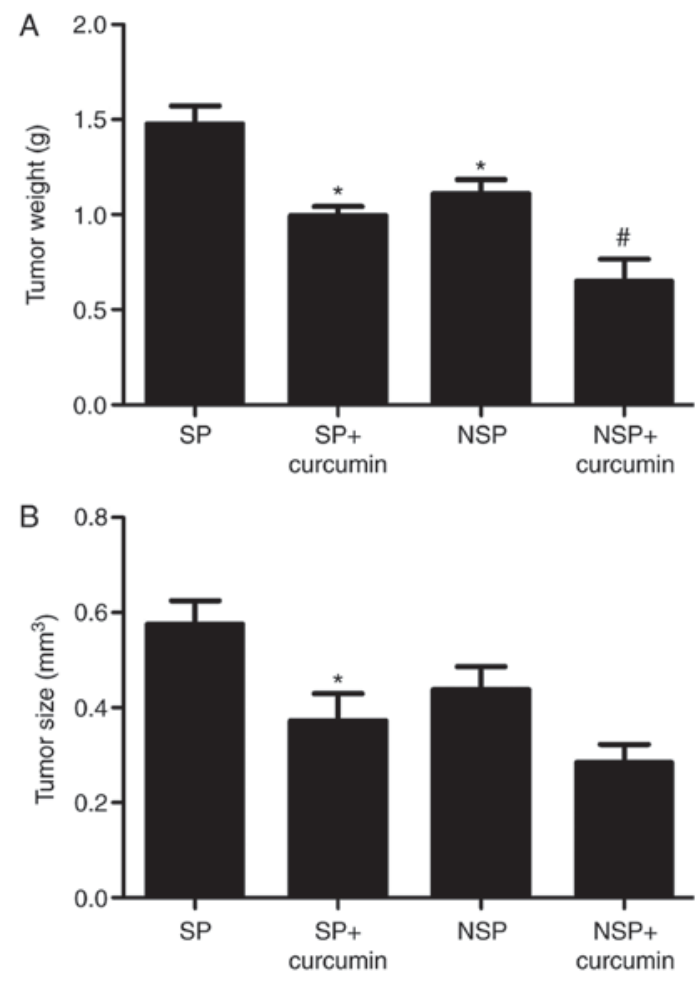

Figure 2. Curcumin effect on tumor growth. (A) The tumor weight of group NSP was notably decreased, compared with group SP. Following treatment with curcumin, the tumor weight of SP cells was decreased, which was less than the decrease of the group NSP+curcumin. (B) The tumor size of group $\mathrm{SP}$ had no significant difference, compared with group NSP. Following treatment with curcumin, the tumor size of the group SP+curcumin was notably decreased, compared with the group $\mathrm{SP} .{ }^{*} \mathrm{P}<0.05$ vs. group $\mathrm{SP},{ }^{\#} \mathrm{P}<0.05$ vs. group NSP. Each experiment was independently repeated three times. SP, side population; NSP, non-SP.

\section{Discussion}

Lung cancer is the leading cause of cancer-associated mortalities in 2012 globally (2). Almost the same number of people from
A
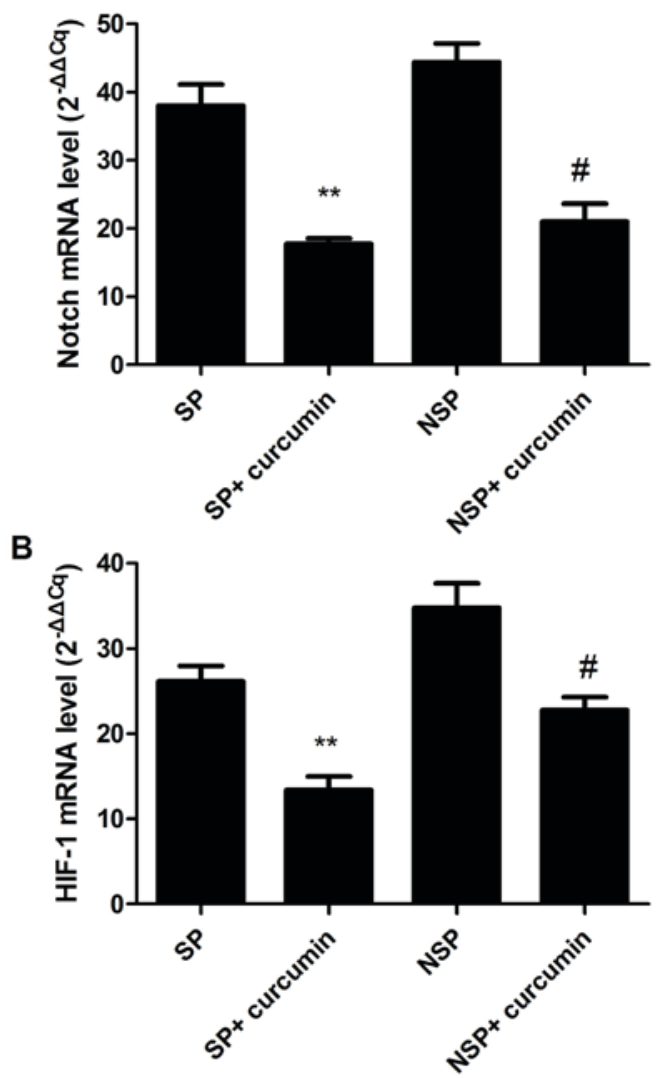

Figure 3. Suppressive effects of curcumin on Notch and HIF-1 mRNA. Curcumin significantly inhibited the mRNA expressions of (A) Notch and (B) HIF-1. Data expressed as mean \pm standard deviation for 10 mice in each group. ${ }^{* *} \mathrm{P}<0.01$ vs. group $\mathrm{SP},{ }^{*} \mathrm{P}<0.01$ vs. group NSP. Each experiment was independently repeated three times. HIF-1, hypoxia inducible factor 1 ; SP, side population; NSP, non-SP.

USA succumbed from lung cancer as succumbed from prostate, breast and colon cancer combined in 2011 (25). Previously, palliative chemotherapy in the metastatic NSCLC setting resulted in modest survival prolongation and preservation of quality of life (26). The ability to exclude Hoechst dye, as defined by SP fraction, was initially indicated in normal hematopoietic cells (27), but was subsequently determined to be present in hematopoietic malignancy and solid tumor types (28). SP cells comprise $<0.1 \%$ of the whole bone marrow cells and are enriched in drug-resistant hematopoietic stem cells (29). Curcumin is an important bioactive component extracted from turmeric rhizome Curcuma longa Linn, which has been frequently studied for its potential anticancer activity in vivo and in vitro. The mechanisms of anticancer include: Inhibition of invasion and metastasis; inhibition of the protein kinases activity; and anti-angiogenesis.

In the present results, the SP colony formation rate $(30.67 \pm 2.57 \%)$ was notably increased, compared with NSP cells $(13.33 \pm 1.76 \%)$, which indicated that the SP fraction cells were enriched in lung cancer cells capable of self-renewal and differentiation with reconstitution of the original cell population. As a result, the tumor weight of group SP was notably increase, compared with group NSP. The tumor volume of group SP was also increased, compared with group NSP, but there was no significant difference. If the observation time was prolonged, 

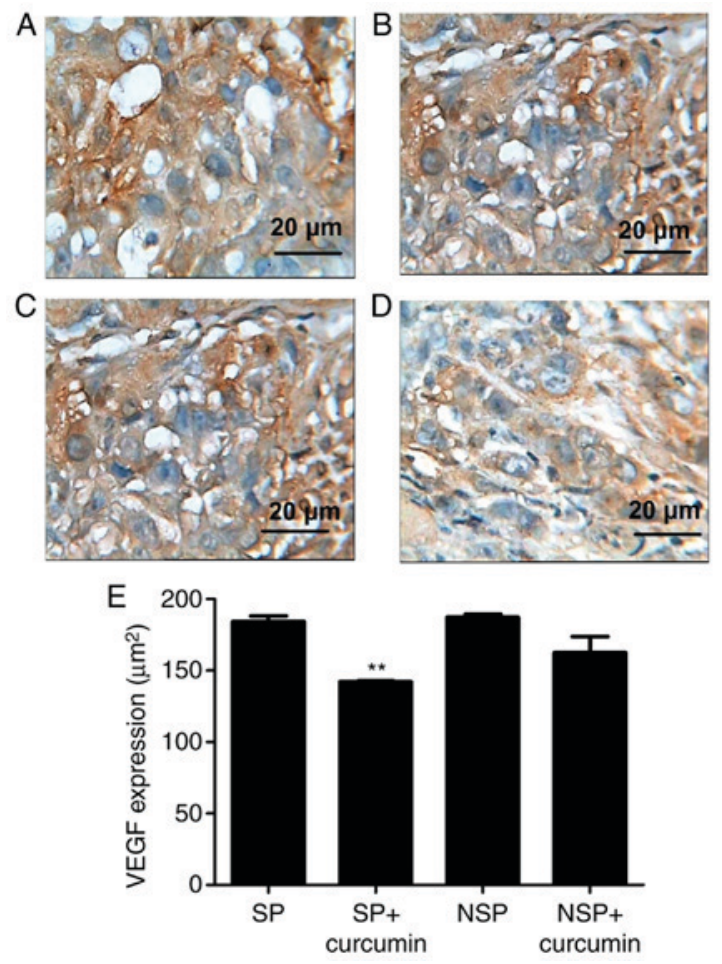

Figure 4. Representative photomicrographs of immunohistochemistry staining on tumor tissue morphology. Immunohistochemistry demonstrated that VEGF was expressed highly in groups (A) SP and (B) NSP, and were primarily located in the cytoplasm and characterized by dark brown staining, however, following eight treatments of curcumin, VEGF immunoreactivity was not prominent in group SP+curcumin (C). VEGF immunoreactivity in (D) group NSP+curcumin had the same prominence as group $\mathrm{SP}+$ curcumin. (E) Bar graphs are depicted as the means \pm standard deviation of three mice per group. Values represent the total positive area. ${ }^{* *} \mathrm{P}<0.01$ vs. group $\mathrm{SP}$. Each experiment was independently repeated three times. The scale bar indicates the magnification. SP, side population; NSP, non-SP; VEGF, vascular endothelial growth factor.

a significant difference may be observed between the two groups. Curcumin may significantly reduce the tumor weight and size in the group $\mathrm{SP}+$ curcumin and group NSP+curcumin. Furthermore, the inhibition degree of group NSP+curcumin was notable increased, compared with group NSP. According to a previous report, SP cells that had the ability to exclude Hoechst dye were associated with increased expression of drug transporters, primarily the $\mathrm{ABC}$ transporters family, including $\mathrm{ABC}$ subfamily $\mathrm{B}$ member 1 and $\mathrm{ABCG} 2$, which are capable of extrusion of the dye from the cell (30). The expression of ABC transporters is associated with drug resistance, which is a characteristic of stem cells from normal and malignant tissues (31). The aforementioned characteristic of SP cells explained why NSP cells had increased sensitivity to curcumin treatment.

Overexpression of VEGF has been determined in NSCLC, and is associated with increased tumor recurrence, metastasis and associated mortality (32). The VEGF pathway activation results in endothelial cell survival, mitogenesis, migration, differentiation and mobilization of endothelial progenitor cells from the bone marrow into the peripheral circulation (33). Additionally, recognition of the VEGF pathway is considered an important mediator of angiogenesis, which has resulted in the clinical study of a number of VEGF-targeted therapies for lung cancer. The coexpression of Notch-1/VEGF has a notable
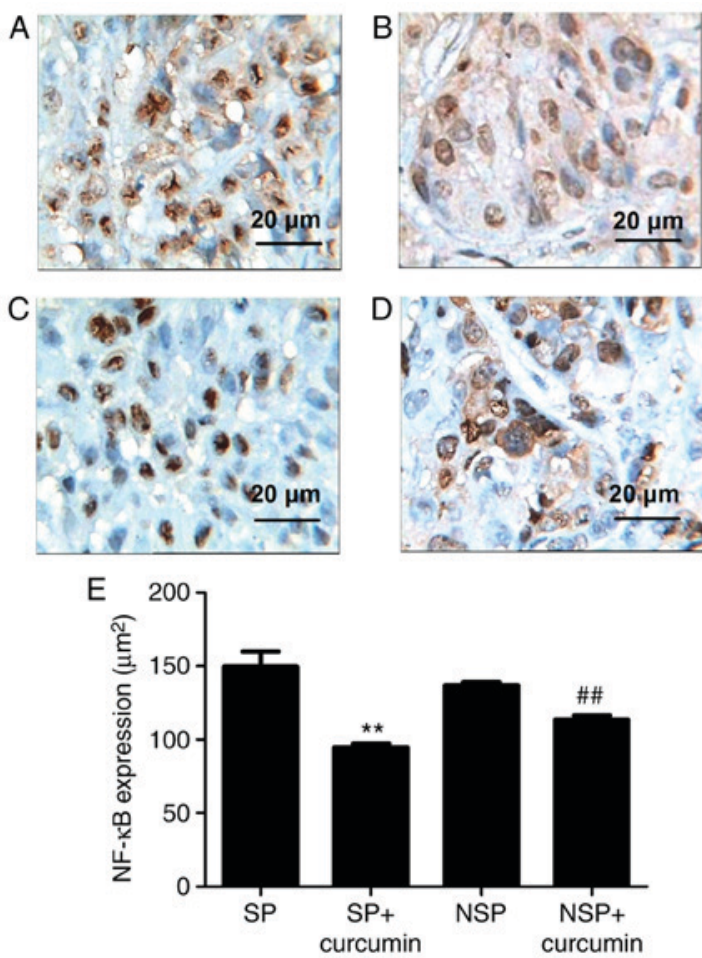

Figure 5. Representative photomicrographs of immunohistochemistry staining on tumor tissue morphology. Immunohistochemistry demonstrated that NF- $\mathrm{B}$ expression was evident in groups (A) SP and (B) NSP, and were primarily located in the cytoplasm and characterized by dark brown staining; however, following eight treatments with curcumin, NF- $\mathrm{BB}$ immunoreactivity was not prominent in groups (C) SP+curcumin and (D) NSP+curcumin, indicating a notable suppression of NF- $\kappa \mathrm{B}$ in tumor tissue. (E) Bar graphs are depicted as the means \pm standard deviation of three mice per group. Values represent the total positive area. ${ }^{* *} \mathrm{P}<0.01$ vs. group $\mathrm{SP},{ }^{\# \#} \mathrm{P}<0.01$ vs. group NSP. Each experiment was independently repeated three times. The scale bar indicates the magnification. SP, side population; NSP, non-SP; NF, nuclear factor.

impact on the survival of lung cancer cells, indicating that Notch-regulated angiogenesis is involved in the metastasis and determines the prognosis of NSCLC (34). The involvement of Notch in lung cancer was experimentally demonstrated in a transgenic mouse model by the alveolar epithelium specific expression of activated Notch (35). Notch is associated with the expression of numerous other cancer-associated proteins, including HIF-1, as a marker of normal lung physiology. Under the condition of hypoxia, Notch 1 could be activated by HIF-1 $\alpha$ in lung adenocarcinoma cells, including A549 cells (36). In the present study, RT-qPCR was used to analyze the levels of Notch and HIF-1 in the A549 cells. Statistical analysis demonstrated that curcumin suppressed the expression of Notch and HIF-1. The significant differences of VEGF expression were observed between the groups treated with and without curcumin. These data are consistent with curcumin-inhibited cancer cell growth associated with the inhibition of angiogenesis.

As a transcription factor, NF- $\mathrm{KB}$ could induce $>200$ genes expression, which are involved in diverse biological processes, including cell survival, cell adhesion, inflammation, differentiation and growth. Tumor tissues from patients with lung cancer expressed high levels of NF- $\mathrm{KB}$ activation, and was significantly associated with disease advancement, regarding Tumor-Node-Metastasis stage, and poor prognosis in patients 
with lung cancer (37). NF- $\mathrm{BB}$ in inflammatory cells activates the secretion of a variety of angiogenesis factors, including VEGF. Immunohistochemistry demonstrated that curcumin inhibited NF- $\kappa \mathrm{B}$ expression in the group of SP+curcumin and group NSP+curcumin. Combined with the result of VEGF and its downstream factors Notch and HIF-1, curcumin suppressed VEGF expression via the inhibition of $\mathrm{NF}-\kappa \mathrm{B}$.

To conclude, the present in vivo experiment demonstrated that treatment with curcumin through intraperitoneal injection inhibited SP and NSP cell-induced lung cancer, which may be associated with the inhibition of angiogenesis. The present study indicated curcumin as a potential alternative for the prevention of tumor growth in lung cancer.

\section{Acknowledgements}

Not applicable.

\section{Funding}

This project was supported by Key projects of Tianjin applied basic and frontier technology research program grant no. 14JCZDJC36900).

\section{Availability of data and materials}

All data generated or analyzed during this study are included in this published article.

\section{Authors' contributions}

XL and SM performed the majority of the experiments, and analyzed and interpreted the data. PY and BS contributed to the cell culture and RT-qPCR. YZ and YS were responsiible for anaesthetizing the animals, removing the tumor tissue, analyzing the animal tumor weight and calculating the tumor size according to the formula. $\mathrm{MH}$ and RM performed the immunohistochemistry. YJ designed the present study, analyzed the data and wrote the manuscript. All authors read and approved the final manuscript.

\section{Ethics approval and consent to participate}

The present experiment was approved by the Animal Care Committee of Tianjin University of Traditional Chinese Medicine (Tianjin, China) and in accordance with the UK Animals (Scientific Procedures) Act of 1986 (18).

\section{Patient consent for publication}

Not applicable.

\section{Competing interests}

The authors declare that they have no competing interests.

\section{References}

1. Ferlay J, Shin HR, Bray F, Forman D, Mathers C and Parkin DM: Estimates of worldwide burden of cancer in 2008: GLOBOCAN 2008. Int J Cancer 127: 2893-2917, 2010.
2. Islami F, Torre LA and Jemal A: Global trends of lung cancer mortality and smoking prevalence. Transl Lung Cancer Res 44: 327-338, 2015.

3. Torre LA, Bray F, Siegel RL, Ferlay J, Lortet-Tieulent J and Jemal A: Global cancer statistics, 2012. CA Cancer J Clin 65: 87-108, 2015.

4. Lam WK, White NW and Chan-Yeung MM: Lung cancer epidemiology and risk factors in Asia and Africa. Int J Tuberc Lung Dis 8: 1045-1057, 2004.

5. Parkin DM, Bray F, Ferlay J and Pisani P: Global cancer statistics, 2002. CA Cancer J Clin 55: 74-108, 2005.

6. Peng H, Ma M and Han B: Survival analysis of 1,742 patients with stage IV non-small cell lung cancer. Zhongguo Fei Ai Za Zhi 14: 362-636, 2011 (In Chinese).

7. Ming X, Feng Y, Yang C, Wang W, Wang P and Deng J: Radiation-induced heart disease in lung cancer radiotherapy: A dosimetric update. Medicine (Baltimore) 95: e5051, 2016.

8. Ho MM, Ng AV, Lam S and Hung JY: Side population in human lung cancer cell lines and tumors is enriched with stem-like cancer cells. Cancer Res 67: 4827-4833, 2007.

9. Hou GX, Liu PP, Zhang S, Yang M, Liao J, Yang J, Hu Y, Jiang WQ, Wen S and Huang P: Elimination of stem-like cancer cell side-population by auranofin through modulation of ROS and glycolysis. Cell Death Dis 9: 89, 2018.

10. Akunuru S, Palumbo J, Zhai QJ and Zheng Y: Racl targeting suppresses human non-small cell lung adenocarcinoma cancer stem cell activity. PLoS One 6: e16951, 2011.

11. Qiu C, Zhang T, Zhang W, Zhou L, Yu B, Wang W, Yang Z, Liu Z, Zou P and Liang G: Licochalcone A Inhibits the proliferation of human lung cancer cell lines A549 and H460 by Inducing G2/M cell cycle arrest and ER stress. Int J Mol Sci 18: pii: E1761, 2017.

12. Feng $\mathrm{H}$, Lu JJ, Wang Y, Pei L and Chen X: Osthole inhibited TGF $\beta$-induced epithelial-mesenchymal transition (EMT) by suppressing NF- $\mathrm{KB}$ mediated Snail activation in lung cancer A549 cells. Cell Adh Migr 11: 464-475, 2017.

13. Li B, Shi C, Li B, Zhao JM and Wang L: The effects of curcumin on HCT-116 cells proliferation and apoptosis via the miR-491/PEG10 pathway. J Cell Biochem 119: 3091-3098, 2018.

14. Wang YL, Ju B, Zhang YZ, Yin HL, Liu YJ, Wang SS, Zeng ZL, Yang XP, Wang HT and Li JF: Protective effect of curcumin against oxidative stress-induced injury in rats with Parkinson's disease through the Wnt/ $\beta$-catenin signaling pathway. Cell Physiol Biochem 43: 2226-2241, 2017.

15. Zhang M, Tang J, Li Y, Xie Y, Shan H, Chen M, Zhang J, Yang X, Zhang $\mathrm{Q}$ and Yang X: Curcumin attenuates skeletal muscle mitochondrial impairment in COPD rats: PGC-1 $\alpha$ /SIRT3 pathway involved. Chem Biol Interact 277: 168-175, 2017.

16. Zhao Z, Yang Y, Liu W and Li Z: T59, a new compound reconstructed from curcumin, induces cell Apoptosis through reactive oxygen species activation in human lung cancer cells. Molecules 23: pii: E1251, 2018.

17. Shimada K, Ushijima K, Suzuki C, Horiguchi M, Ando H, Akita T, Shimamura M, Fujii J, Yamashita C and Fujimura A: Pulmonary administration of curcumin inhibits B16F10 melanoma lung metastasis and invasion in mice. Cancer Chemother Pharmacol 82: 265-273, 2018.

18. Li Y, Zhang S, Geng JX and Hu XY: Curcumin inhibits human non-small cell lung cancer A549 cell proliferation through regulation of Bcl-2/Bax and cytochrome C. Asian Pac J Cancer Prev 14: 4599-602, 2013.

19. Liu F, Gao S, Yang Y, Zhao X, Fan Y, Ma W, Yang D, Yang A and Yu Y: Curcumin induced autophagy anticancer effects on human lung adenocarcinoma cell line A549. Oncol Lett 14: 2775-2782, 2017.

20. Hollands C: The Animals (scientific procedures) Act 1986. Lancet 8497: 32-33, 1986.

21. Wo XD, H XQ and G CX: Long term toxicity test of curcumin. J Zhejiang College TCM 24: 61-65, 2000 (In Chinese).

22. Zhuang HW, Mo TT, Hou WJ, Xiong GX, Zhu XL, Fu QL and Wen WP: Biological characteristics of CD133(+) cells in nasopharyngeal carcinoma. Oncol Rep 30: 57-63, 2013.

23. Yu L, Garg HG, Li B, Linhardt RJ and Hales CA: Antitumor effect of butanoylated heparin with low anticoagulant activity on lung cancer growth in mice and rats. Curr Cancer Drug Targets 10: 229-241, 2010.

24. Livak KJ and Schmittgen TD: Analysis of relative gene expression data using real-time quantitative PCR and the 2(-Delta Delta C(T)) method. Methods 25: 402-408, 2001. 
25. Dela Cruz CS, Tanoue LT and Matthay RA: Lung cancer: Epidemiology, etiology, and prevention. Clin Chest Med 32: 605-644, 2011.

26. Hopwood P and Stephens RJ: Symptoms at presentation for treatment in patients with lung cancer: Implications for the evaluation of palliative treatment. The Medical Research Council (MRC) Lung Cancer Working Party. Br J Cancer 71: 633-636, 1995.

27. Goodell MA, Brose K, Paradis G, Conner AS and Mulligan RC: Isolation and functional properties of murine hematopoietic stem cells that are replicating in vivo. J Exp Med 183: 1797-1806, 1996.

28. Hadnagy A, Gaboury L, Beaulieu R and Balicki D: SP analysis may be used to identify cancer stem cell populations. Exp Cell Res 312: 3701-3710, 2006.

29. Sales KM, Winslet MC and Seifalian AM: Stem cells and cancer: An overview. Stem Cell Rev 3: 249-255, 2007.

30. Kim M, Turnquist H, Jackson J, Sgagias M, Yan Y, Gong M, Dean M, Sharp JG and Cowan K: The multidrug resistance transporter ABCG2 (breast cancer resistance protein 1) effluxes Hoechst 33342 and is overexpressed in hematopoietic stem cells. Clin Cancer Res 8: 22-28, 2002.

31. Szakács G, Paterson JK, Ludwig JA, Booth-Genthe C and Gottesman MM: Targeting multidrug resistance in cancer. Nat Rev Drug Discov 5: 219-234, 2006.
32. Ferrara N: The role of vascular endothelial growth factor in pathological angiogenesis. Breast Cancer Res Treat 36: 127-137, 1995.

33. Hicklin DJ and Ellis LM: Role of the vascular endothelial growth factor pathway in tumor growth and angiogenesis. J Clin Oncol 23: 1011-1027, 2005.

34. Yuan X, Wu H, Han N, Xu H, Chu Q, Yu S, Chen Y and Wu K: Notch signaling and EMT in non-small cell lung cancer: Biological significance and therapeutic application. J Hematol Oncol 7: 87, 2014.

35. Allen TD, Rodriguez EM, Jones KD and Bishop JM: Activated Notch1 induces lung adenomas in mice and cooperates with Myc in the generation of lung adenocarcinoma. Cancer Res 71: 6010-6018, 2011

36. Guo L, Zhang T, Xiong Y and Yang Y: Roles of NOTCH1 as a therapeutic target and a biomarker for lung cancer: Controversies and perspectives. Dis Markers 2015: 520590, 2015.

37. Karin M and Greten FR: NF-kappaB: Linking inflammation and immunity to cancer development and progression. Nat Rev Immunol 5: 749-759, 2005. 